\title{
Analyticity and Justification in Frege
}

\section{Erkenntnis}

An International Journal of Analytic Philosophy

\section{ISSN 0165-0106}

Volume 73

Number 2

Erkenn (2010) 73:165-184

DOI 10.1007/

s10670-010-9248-9

\section{E R K E N N T N I S}

AN INTERNATIONAL JOURNAL OF

ANALYTIC PHILOSOPHY

Editor-in-chief: Hans Rott

Editors: Wolfgang Spohn, Patrick Suppes

Springer 
Your article is protected by copyright and all rights are held exclusively by Springer Science+Business Media B.V.. This e-offprint is for personal use only and shall not be selfarchived in electronic repositories. If you wish to self-archive your work, please use the accepted author's version for posting to your own website or your institution's repository. You may further deposit the accepted author's version on a funder's repository at a funder's request, provided it is not made publicly available until 12 months after publication. 


\title{
Analyticity and Justification in Frege
}

\author{
Gilead Bar-Elli
}

Received: 26 December 2007/ Accepted: 20 August 2010/Published online: 14 September 2010

(C) Springer Science+Business Media B.V. 2010

\begin{abstract}
That there are analytic truths may challenge a principle of the homogeneity of truth. Unlike standard conceptions, in which analyticity is couched in terms of "truth in virtue of meanings", Frege's notions of analytic and a priori concern justification, respecting a principle of the homogeneity of truth. Where there is no justification these notions do not apply, Frege insists. Basic truths and axioms may be analytic (or a priori), though unprovable, which means there is a form of justification which is not (deductive) proof. This is also required for regarding singular factual propositions as a posteriori. A Fregean direction for explicating this wider notion of justification is suggested in terms of his notion of sense (Sinn) - modes in which what the axioms are about are given — and its general epistemological significance is sketched.
\end{abstract}

\section{Analyticity and Justification in Frege}

The doctrine of analyticity - that there are analytic truths - has been offered as an answer to the problem of apriority: How can there be truths whose knowledge and justification do not rely on (empirical) experience. The relationships between truth, knowledge and justification are thus at the focus, and should direct us in any appreciation of the doctrine concerned. Analyticity is often couched in terms of meaning relations and of truth in virtue of meanings. This is a quite standard conception at least since Carnap. Frege, as we shall see presented a different notion, and we shall later dwell on its advantages over the standard one. Frege's conception of analyticity has been, however, widely misconstrued, and we shall need to take some pains in clarifying it. In particular, the nature of justification, which is central

G. Bar-Elli (ه)

Department of Philosophy, The Hebrew University of Jerusalem, Jerusalem, Israel e-mail: barelli@mscc.huji.ac.il 
to this conception, and its role in founding the basic truths (axioms) of a domain, should be explicated.

Frege's philosophical program in The Foundations of Arithmetic (FA) ${ }^{1}$ aims at establishing that arithmetic is analytic, in the sense he gives to this term. There is, however, a difficulty, in fact a seeming incoherence, at the basis of the program: The notions of analytic and a priori, Frege states, apply only to what is justifiable and to its justification. Basic truths cannot be proved. Hence, if proof were the only pertinent form of justification, such truths, including logical ones, could not be said to be analytic. Likewise, a non-logical basic truth, like a geometrical axiom, could not be a priori, and an unprovable singular factual truth could not be a posteriori. But this seems to be unacceptable. I shall present the difficulty and propose a way out, which, I believe, is important for understanding some other fundamental topics in Frege's philosophy.

The epistemic status of basic truths and axioms raises difficult problems on any view, but particularly in a foundationalist approach such as Frege's. ${ }^{2}$ The Fregean direction that I suggest for answering the above difficulty, which admittedly goes at some points beyond what Frege explicitly said, relies on construing Fregean sense (Sinn) as a special cognitive relation to things in the world in a way that makes it fit to belong within the justification-space of what is objective-logical and mathematical basic truths included.

The general philosophical significance of Frege's notion of analyticity, as presented here, lies not only in this epistemic point, but also in suggesting an answer to "the problem of apriority", which is in full harmony with a realistic conception of truth, and with respecting a principle of the "homogeneity of truth", where its main advantage over the standard conception of analyticity lies.

\section{Proof and Justification}

In the central $\S 3$ of FA Frege introduces his notions of a priori, a posteriori, analytic and synthetic. These notions, Frege emphasizes, concern not the content of a judgment but its ground and justification (Berechtigung):

These distinctions between a priori and a posteriori, synthetic and analytic, concern, as I see it, not the content of the judgment but the justification for making the judgment [die berechtigung zur Urteils-faellung]. Where there is no justification, the possibility of drawing the distinctions vanishes. [ $\mathrm{Da}$, wo diese fehlt, fällt auch die Möglichkeit jener Einteilung weg. Emphasese added.]

\footnotetext{
${ }^{1}$ Frege, FA. I emphasize "philosophical" to shunt here aside the formal achievements and the formal difficulties involved in FA, which are not our concern here.

2 The question was already discussed by Aristotle, who claimed that the foundations of a demonstration are not demonstrable - see Aristotle (1941) Posterior Analytics, 72b 10-18. He adds that one cannot ask a reason for everything, (Met. 1011a).
} 
And later, again: "When a proposition is called a posteriori or analytic in my sense, it is a judgment about the ultimate ground upon which rests the justification for holding it to be true".

I shall call this "principle J".

Analytic judgments are then introduced, in the same section, the next paragraph, thus: "The problem now becomes that of finding the proof of the proposition, and of following it back to the primitive truths. If, in carrying out this process, we come only on general logical laws and on definitions, then the truth is an analytic one". Evidently, as Frege often explains, in this "backward process" we must eventually come on basic truths or axioms that cannot be proved. ${ }^{3}$ It should be noted that this is not strictly a definition (of analytic); it is a conditional that leaves open the possibility of there being an analytic truth that is not proved, and may even be unprovable. ${ }^{4}$ Bearing this in mind, we shall however, for simplicity, call these conditionals "definitions". Likewise, in the definition of a priori judgment Frege says: "If, on the other hand, its proof can be derived exclusively from general laws, which themselves neither need nor admit of proof [die selber eines Beweises weder faehig noch beduerftig sind], then the truth is a priori" (emphasis added). This seems to imply, in light of principle $J$, that if deductive proof were the only form of justification, the basic truths (the axioms) would be neither analytic nor a priori, which is hard to accept-both in itself and as Frege's view.

What is the relationship between the notions of proof and of justification? Proof, for Frege is deductive inference from truths. He was perhaps the first to formalize and sharply define this notion, where it is presented as a sequence of truths, each being an axiom or derivable from previous truths by means of explicit rules of inference. Proof is evidently a paradigmatic form of justification, but is proof (i.e. deductive inference) the only form of justification? It may seem that justification (Berechtigung), at least in logic and mathematics, just means proof (Beweis), and this is the way Frege's position has been generally understood..$^{5}$ I leave here aside what may be called "pragmatical justifications" that pertain to a whole system of axioms - its deductive power, completeness, etc.- and rather focus on axioms taken individually, in which, for Frege, the primary notion of justification consists. There is an important connection between the two, but its discussion will take us too far afield, and I shall not pursue it here. ${ }^{6}$

\footnotetext{
3 See for instance "Logic in Mathematics", in PW, 203-250, particularly 203-5. Frege, though, was well aware already in Begriffsschrift that there may be alternative (equivalent) systems such that an axiom in the one is provable in another. See Begriffsschrift, e.g. §13. Cf. also PW, p. 205.

4 In "Frege on Apriority" (Burge 2005, 356-387) Burge claims that these are definitions stating sufficient and necessary conditions for analyticity and apriority, and gives some reasons for thinking so (359). I remain unconvinced. The reasons given in the text for not thinking these formulations as stating necessary conditions-leaving open the possibility of regarding the axioms as analytic-seem to me to overweigh those given by Burge.

5 See e.g. Dummett (1991), pp. 23, 25. Dummett emphasizes that "all justification proceeds by deductive reasoning... he [Frege] does not allow for the possibility of any other form of justification" (25). Cf. also Burge (1998), e.g. p. 315.

6 The general direction of the connection can be appreciated by realizing that there is an internal connection between mode of being given, and being a constituent of thought; these are Frege's two main
} 
The above definitions, as the emphasized part of the definition of a priori makes explicit, presume that in the process of finding or presenting a proof we eventually come on basic truths (or judgments) that "neither need nor admit of proof". Frege evidently did not regard a one-line statement of an axiom as a proof of it; definitely not when proof is regarded as justification. Nor did he admit of hypothetical proofs and reduction ad absurdum, and he would probably object to Gentzen-type proof, for he insisted that any proof must be based on true judgments. It thus appears that if proof were the only form of justification (in mathematics and logic), this would mean, in light of principle $\mathrm{J}$, that the above distinctions do not apply to these basic truths or judgments: since they are not provable they would be neither analytic nor synthetic, neither a priori, nor a posteriori. Likewise, particular unprovable facts would be neither synthetic nor a posteriori.

\section{The Notions of Analytic and A Priori Should Apply to Axioms}

This conclusion, however, seems unacceptable, and contrary to what Frege's position is generally taken to be: Traditionally, logical axioms are the paradigm of analytic truths, and geometrical axioms - the paradigm of a priori ones. ${ }^{7}$ This seems also to be the basis of the rationale of Frege's distinctions here: If logical axioms were not analytic, and geometrical ones were not a priori, what would be the point of defining analyticity and apriority as he does? Moreover, Frege was aware, of course, of the possibility of alternative equivalent axiom systems-both in geometry and in logic (Bs. §13). This means that what is an axiom in one system may be provable (and hence, a priori or analytic) in another. Proof is likewise relative to a system. It is implausible however to suppose that the notions of analyticity and a priority are thus relative to a system. This may also impel one to regarding the axioms as analytic, or a priori. In addition, the justifiability of axioms (including logical ones) may seem to be problematic independently of the applicability of the notions of analytic and a priori to it, and much of what we shall say pertains to it directly. But presuming this applicability our difficulty becomes even more acute. Was Frege then so careless in presenting principle $\mathrm{J}$ in this central section of FA? And if not-how should we construe it?

In his FPM (1991) Dummett says that "with uncharacteristic carelessness, Frege has framed his definition [of analyticity] so as not to cover the initial premises themselves" (p. 24). This is quite surprising. For Dummett, as we have seen, proof is the only relevant form of justification (see note 5 above); hence, he should have

\footnotetext{
Footnote 6 continued

characterizations of his notion of sense. A thought, however, is logically constituted by its inferential relations. This is explicit with regard to Frege's earlier notion of content (of a judgment) in Begriffsschrift, §3, but is also true, I believe, of his later notion of thought. Hence, modes of presentation, which are the constituents of thoughts, cannot be detached from this logical space of inferential relations. For a fuller account, cf. Bar-Elli (2001). For a somewhat different approach, couched in terms of the connection between "pragmatical justification" of a system, and the self-evidence of an axiom, see Burge (1998), §§III-IV.

7 The apriority of the axioms of geometry is presumed, for instance, in Dummett (1981), p. 464.
} 
regarded principle $\mathrm{J}$, so much emphasized by Frege, as explicitly excluding the applicability of the notions of analytic and a priori to axioms (as well as a posteriori to particular facts). It is not an oversight on Frege's part in formulating the "definitions"; it is principle $\mathrm{J}$ that is the source of the problem, and it cannot be regarded as an oversight.

Immediately after the above quoted sentence, Dummett says that Frege's definitions can be obviously "extended" to rate particular facts as a posteriori and axioms as analytic or a priori. He does not formulate the obvious extension explicitly. What would it be like? Dummett does not mean here to emend Frege's notion of proof. He obviously thinks of a slight extension in the definitions of "analytic" etc. to rate basic laws of logic as analytic and axioms of geometry as a priori. But unless justification is wider than proof, any such extension would fly flatly in the face of principle J. The axioms cannot be proved. Hence, if the extended definitions would still rate them as analytic or a priori (e.g. by stipulating that being an axiom is sufficient for that), this would mean, in light of principle $\mathrm{J}$, that there is a way of justifying them other than by proof. Hence, when principle $\mathrm{J}$ is given its due weight, Dummett's correct view that axioms must have been regarded by Frege as analytic or a priori, and particular facts must have been regarded to be a posteriori, implies, in contrast to what Dummett suggests, that the notion of justification concerned in principle $\mathrm{J}$ must be wider than that of proof. ${ }^{8}$

Similar comments apply to other theorists. Boghossian, for instance, is even more sweeping than Dummett and says about all logical truths-not only the axiomsthat their apriority (and analyticity) is simply assumed and is unaccountable:

So our question concerns only the most elementary laws of sentential or firstorder logic. How do we know a priori, for example, that all the instances of the law of non-contradiction are true, or that all the instances of modus ponens are valid?

As I noted above, Frege thought it obvious that there could be no substantive answer to such questions; he was inclined, therefore, to take appearances at face value and to simply assume the apriority of logic. (Boghossian, 1996)

This, again, is in direct defiance of Frege's explicit view expressed by principle J.

Our problem, to prevent a possible misunderstanding, is not how to "define" a logical truth. Frege's notion of analyticity obviously assumes that of logical law, and the distinction between analytic and other a priori truths assumes our ability to identify, in the process of justification, logical from other general laws. Our problem

\footnotetext{
${ }^{8}$ In his 1998 Burge says that Frege "neglects to formulate his notions of analyticity and apriority so as to either include or rule out the foundations of logic" (310; in Burge 2005, p. 322). In note 6 added there he agrees with Dummett that this was an "oversight" on Frege's part, easily emended so as to count the axioms analytic and a priori. In his "postscript to 'Frege on Apriority" " he withdraws this admission, and says that Frege intentionally followed suit with Kant in not regarding the axioms of logic as analytic, the reason being that "such laws are not subject to analysis" (Burge 2005, 388-389). I agree with Burge's recent view that this is not an oversight. Paying attention to the emphasized principle $\mathrm{J}$ (which Burge doesn't mention) is sufficient to show this conclusively. Burge, however, concludes that the axioms of logic are not analytic, and axioms of geometry are not a priori. This, as I argue in the text, seems to me unacceptable, and I suggest another way: proof, formal deductive demonstration, is not the only form of justification. The axioms can be justified, but not by proving them.
} 
is rather to explain how the notions of analytic and a priori can be applied to axioms and other basic truths, and what notion of justification is appealed to here.

\section{Self-Evidence, Justification and Sense}

Some exceptions notwithstanding (e.g. BL p. 127), Frege scarcely talks of axioms in terms of the traditional idiom of self-evidence. He probably heard in this traditional term some psychological overtones he disliked. ${ }^{9}$ When he does use it, it is usually in critically discussing others' views (e.g. FA §5). He usually talks of axioms as not admitting, and not in need of proof, and sometimes adds that their truth is independent of other truths (e.g. PW 168). Many scholars, however, do ascribe to Frege the view that axioms, or basic truths as he calls them, are self-evident. ${ }^{10}$ But this, even if true, doesn't seem to solve our difficulty. For first, the relevant notion of self-evidence is far from clear. Frege probably didn't regard the axioms of arithmetic (the so-called Peano axioms) as self-evident in the traditional sense, for his main program was based on the assumption that they are provable, by his definitions, in logic. ${ }^{11}$ It is difficult to see in what sense Frege could deny selfevidence to the axioms of arithmetic, and say both of the axioms of (Euclidean) geometry and of his system in The Basic Laws of Arithmetic (BL) ${ }^{12}$ that they are self-evident. Moreover, Frege was of course aware of the problematic status of e.g. the axiom of parallels in the eyes of many able mathematicians, and of his own qualms about "axioms" other people regarded as self evident, and even about his own axiom $\mathrm{V}$ of $\mathrm{BL}$ - before the discovery of the contradiction, and after it.

For our concerns here, what is perhaps more pertinent is that it is not clear in what way we can take such self-evidence as a justification. We have seen that on the widely accepted assumption that justification is proof, the basic truths have no justification. The mere dubbing of axioms as self-evident, or even recognizing them as such, is therefore no solution to our difficulty. Being self-evident is never presented by Frege as a proof of a truth, but at most as a reason for its not needing a proof. Therefore, if it is a form of justification, this would just show again that justification is a wider notion than proof. In any case, it would need further clarification that should explicate in what way recognizing a basic truth as selfevident provides a justification for it. Indeed, I would propose much of the following as pointing at the general direction a partial explication of this sort may take. ${ }^{13}$

Frege's repeated idiom, after saying that the basic truths cannot be proved, that they are "not in need of proof", does not resolve our difficulty either. For, assuming

\footnotetext{
9 In his (1998, §IV) Burge, quite convincingly, suggests a distinction between a subjective notion of selfevidence, which he calls "obviousness", and an objective one, which he explicates in terms of an ideal mind. When using self evidence as characteristic of axioms, Frege refers to the latter, not the former.

${ }^{10}$ See for instance, Burge (2001), particularly pp. 57, 59, 61, (2005), 360-364; also his earlier (1998), particularly pp. 327 ff. Cf. Bar-Elli (2001), 106-109.

11 Cf. Burge (1998), p. 336.

12 Cf. also Frege's Begriffsschrift.

13 For a fuller account, see Bar-Elli (2001).
} 
that justification is proof, in order for the notions of analytic and a priori to be applicable, the only question, as we saw, is whether and how they can be proved. Whether or not they are in need of proof is a different question.

It seems therefore that the most plausible way out of the difficulty is to realize that Frege held a wider notion of justification-even in logic and mathematicsthan proof. Proof and deductive inference are evidently a basic form of justification. But they do not exhaust it. Axioms and other basic judgments that cannot be proved may yet be justifiable. Frege didn't use "analytic" after FA, but the problem of the justifiability of basic truths we have outlined is central to his position and to the rationale of his logicistic program in general. It is central to his position even at the very late phase in which he probably gave up his logicistic approach to arithmetic. We shall therefore not sin to the spirit of his view by using these terms with regard to his position after FA as well. Realizing a notion of justification wider than proof would enable us to understand how Frege could have held that the axioms of logic and of geometry are unprovable, and yet analytic and a priori respectively. I shall outline the nature of this other way in the sequel.

There is, moreover, other textual evidence for believing Frege to have held such a view, which may also hint at the nature of such a justification:

Now the grounds which justify the recognition of a truth often reside in other truths which have already been recognized. But if there are any truths recognized by us at all, this cannot be the only form that justification takes. There must be judgments whose justification rests on something else, if they stand in need of justification at all. And this is where epistemology comes in ("Logic", in Posthumous Writings (PW), p. 3; emphasis added). ${ }^{14}$

This passage has been often ignored in the relevant literature, and has hardly been taken seriously. But in light of the above difficulty, in the heart of the philosophical program of FA, it should, I believe, be given its due weight. Frege does not say here what this "something else", on which non-deductive justification may rest, is, besides saying that it is epistemic. This may be an important clue; as I shall suggest, it in fact refers, without using yet the later terminology for that, to his notion of sense, or mode in which something is given to us. ${ }^{15}$ I shall add some more evidence for this, with regard to geometry, in the sequel.

\section{Justification and Objectivity}

I shall later return to the nature of this kind of justification. Before doing this, let me mention that recognizing this wider notion of justification is important for

\footnotetext{
14 The editors of the Nachlass date this between 1879 and 1891. Since until 1882 Frege's writings were centered on the Begriffsschrift of (1879), I surmise that this piece can be reasonably dated closer to FA, which was published in 1884 , or after it.

15 It should be noted that the general idea of sense is evident not only in parts of FA, but already in Bs, $\S 8$, where Frege argues that understanding identity statements involve recognizing that names for the same content may differ in their Bestimmungsweise - the ways they determine it, which is somewhat akin to his later notion of ways of being given (Art des Gegebenseins), or sense, see Bar-Elli (2006).
} 
understanding fundamental features of Frege's philosophy, other than the status of arithmetic as analytic and a priori-be this important as it is-like his notion of objectivity, and the role of his notion of sense in logic. The criterial sign of objectivity, for Frege, is justification or justifiability: something is objective insofar as it is justifiable or as statements about it are. The first of the three fundamental principles in the Introduction to FA is the demand "Always to separate sharply the psychological from the logical, the subjective from the objective" ["Das Psychologische von dem Logischen, das Subjective von dem Objectiven scharf zu trennen", P. x]. This is one principle, and the two distinctions are parallel. It appears therefore that the objective is the logical. And logic, as Frege makes clear on numerous occasions, has to do with the justification of propositions. ${ }^{16}$ The main tenor of FA is to establish the objectivity (or "objective factuality", as Frege sometimes says) of arithmetic by clarifying the grounds or justification of arithmetical propositions. Logic, objectivity and justification thus form an inseparable triad for Frege.

The connection between logic and objectivity, seeing logic as constitutive of objectivity, raises, however, a question, for in its simple sense (and so also in Frege) what is objective is what is "out there" in the world, or what concerns objects in the world; and Frege often further characterizes the objective as what is true independently of recognizing it as such, or independently of the judging subject, and as what is communicable and accessible to different people from different perspectives, etc. ${ }^{17}$

What, then, is the relationship between these two aspects of the objective- the logical aspect, on the one hand, and being concerned with and based on objects in the world, on the other? In trying to answer this, I believe, we must appeal to the third element in the above triad-the internal connection between objectivity and justification. What is objective is only what is justifiable or what is used in a justification; in short, what is in the justification-space. Justification, however, is the business of logic. Logic is thus not only itself objective in this sense, but is constitutive of objectivity by setting up the standards for justification (and hence for objectivity); it is what constitutes the justification-space, and hence-the objective. But being, as it is, inseparable from truth, it also pertains to the world-involving factors-objects and their relations - in a way that is communicable and objectiveas belonging to the justification space. These objects and relations are always given to us in particular ways, which Frege called senses (Sinne), and which figure prominently in justification of claims about them.

\section{Logic and Justification}

The main task Frege set up for himself was to establish the objectivity of various domains-particularly arithmetic. In light of the above, this meant for him

\footnotetext{
${ }^{16}$ See the Preface to Bs; FA §3; PW, p. 3; ibid. 147.

${ }^{17}$ See for instance FA §26, BL xvii/15, PW 149/137. Cf. Bar-Elli (1996), Chap. 2, particularly pp. 36-47.
} 
presenting statements in this domain as justified or at least justifiable. Logic was both the paradigm and the primary means of such justification. Deductions and proofs are chains of justifications of some truths on the basis of others-whether within logic or in other domains. In a narrow sense of logic the standards of justification it sets up are those of proof, or deductive inference. And one of Frege's important achievements is that he, perhaps for the first time, explicated in detail the notion of formal proof, and set its standards (this is not to imply that proof, for him, was merely a formal notion; it certainly wasn't). But as noted above, and this is the main point, there is another level of justification, which is not strictly deductive, but can still be considered logical in a wider sense, for logic in this wide sense is the theory of justification or justifiability. ${ }^{18}$ This other level is where the basic truths of a domain are justified not by being proved or derived from more fundamental truths (since there aren't any), but in being shown to be clear and evident by the ways "their objects", the things they are about, are given to us. One can even say that these basic truths are justified in expressing aspects or features of the ways "their objects" are given us, or, in other words, by the modes of presentation or senses (Sinne) of the things they are about. ${ }^{19}$

Explaining this in detail would require extensive elucidation of Frege's notion of sense, which would take us far beyond the scope of this article. Let me just say that Frege's notion of sense is constituted by ontological, epistemic and linguistic layers, which both constrain and fertilize each other. It is thus at the center of a rich and loaded philosophical junction. Central in this picture is the idea that things in the world are given to us in particular ways, which are, on the one hand, expressed, and on the other, constrained by the senses of the terms referring to those things. They crucially figure, therefore, in justifying basic truths about those things.

Frege's primary example of this is geometry. Geometrical truths (theorems) are objective in being justifiable. They are justified, through logical proofs, on the basis of other geometrical truths, and ultimately by the basic truths, or axioms of geometry. But what about these axioms themselves? Obviously, they cannot be proved or derived logically from more basic truths. Should we say they are not justifiable, and therefore not objective, and not a priori? Certainly not: This would ruin the objectivity of the whole edifice built on the basis of these axioms. ${ }^{20}$ It is here that this other form of justification gets in: The axioms are justified on the basis of the ways their objects, the objects of geometry, are given to us: "So long as I

\footnotetext{
18 See for instance, "Logic", in PW, p. 3; “17 Key Sentences...”, PW, 175; cf. also Bar-Elli (2001).

19 I talk of "objects" and "things an axiom is about" rather loosely here. They include not only objects in the narrow sense, but also functions and concepts. Axioms (whether analytic or only a priori) are usually general judgments, and as such are strictly about concepts. Only rarely (as in e.g. axiom V of BL) about objects. However, in a wider sense we can say that the axioms of arithmetic are about numbers, and those of geometry - about points and lines. This looser way of talk does not affect the main point made here.

${ }^{20}$ Recall the crucial passage from "Logic" (PW 3) cited above: “... But if there are any truths recognized by us at all, this cannot be the only form that justification takes ..." Cf. also FA §26. Already in Bs (§13) Frege spoke of the axioms (the basic truths) as comprising the "kernel" of the whole system. He emphasize this again with regard to mathematics e.g. in "Logic in Mathematics", PW p. 204-5. With regard to geometry, he insists on the truth of the axioms, and on holding either Euclidean or nonEuclidean geometry to be true- "No man can serve two masters" ("On Euclidean Geometry", PW, p. 169).
} 
understand the words 'straight line', 'parallel' and 'intersects' as I do, I cannot but accept the parallels axiom... Their sense is indissolubly bound up with the axiom of parallels" ("Logic in Mathematics", PW 247). ${ }^{21}$ The fact that Frege insisted that geometrical objects and relations are given by "intuition" does not weaken, but rather validates my point. For, it shows that how these objects are given is central to the justification of the axioms. An early recognition of the importance of the way something is given to us to justifying truths about it is present, without yet using his mature notion of sense, already in Begriffsschrift. In $\$ 8$ there (on Identity) Frege gives a geometrical example of an identity (of two points on a circle), and remarks that the ways these are determined (Bestimmungsweise), which is close to his later ways of being given, is essential to the justification (Rechtfertigung) of the identity. $^{22}$ In a piece he probably wrote in the last year of his life Frege wrote: "From the geometrical source of knowledge flow (fliessen) the axioms of geometry" (PW, 273). The axioms then "flow" from something; they have grounds or justification. And this, I suggest, is basically the ways the geometrical things they are about are given-the senses of their terms.

Another example of this kind of reasoning in FA is the following. Frege considers the equivalence: "The direction of $a$ is the direction of $b$ if and only if $a$ is parallel to $b "((\mathrm{D}(a)=\mathrm{D}(b) \equiv a / / b)$. He mentions the possibility of using this for defining parallelism in terms of directions, and rejects it on the ground that such a definition does not respect, as it should, the ways things are given to us: "Everything geometrical must be given originally in intuition" (FA, p. 75). Parallelism, he thought, is given in intuition; directions are not. Therefore, defining the former in terms of the latter is "to reverse the true order of things" (ibid.). This principle of respecting the ways things are given to us applies to the axioms as well. The axioms, one may say, express at least some basic aspects of these modes of presentation of the geometrical objects. ${ }^{23}$

Frege sets himself the task of constructing something similar for arithmetic, thus establishing solid foundations for mathematics. The defects he found in arithmetical texts of his day were not only that many arithmetical proofs were unclear or faulty, and that definitions lacked the precision and rigor he required for them, but also that the whole science of arithmetic lacked an objective basis. To remedy the former fault it was necessary, according to Frege, to present arithmetical truths in a systematic logical language that would render their proofs transparent and their basis detectable. That was obviously the task of constructing a logical language. In principle, this was accomplished by the logical language of his Begriffsschrift (1879). But the latter deficiency was no less severe, and called for no lesser a task: i.e. presenting the objects of arithmetic, the objects the axioms are concerned with (namely, numbers), in such a way that the axioms themselves are justifiable. This, in

\footnotetext{
${ }^{21}$ I thus think that Burge, for instance, in grounding Frege's belief in the truth of Euclidean geometry just in its longevity, underrates the force of this argument (cf. Burge 1998, p. 327).

${ }^{22}$ This, with a comparison to his later view in "On Sense and Reference" is elaborated in Bar-Elli (2006)

${ }^{23}$ Scholars have debated on whether this way of being given is basically Kantian spatial intuition, and whether Frege can be regarded as a Kantian in this respect. I shall not discuss this here. Cf. Dummett (1981), pp. 463-470.
} 
general and programmatic terms, was achieved in (or at least, was the aim of) FA, and more rigorously, and in more detail, in BL.

Frege's logicism - the program of presenting arithmetic as derivable from logic (and appropriate definitions)—was designed to solve both problems. Expressing arithmetical truths in the language of Begriffsschrift enabled him to present their proofs completely and systematically. But it served a further and, in a way, more basic aim. Being convinced that there is no other way in which numbers can be construed that can justify the axioms of arithmetic, Frege thought that the only way to achieve this goal was to construe them as logical objects. This, together with a logical rendering of other arithmetical notions, would enable us to present and justify the arithmetical axioms as logical truths. Again, the crucial step here is the double move of regarding the axioms, the basic truths of arithmetic, as being about objects of a certain kind (numbers), and of regarding the ways these objects are given us as grounds for justifying these axioms, thus establishing the objectivity of the whole edifice of arithmetic.

This double move may explain Frege's persistent view that establishing the objectivity of arithmetic requires an explication of the nature of numbers and the way they are given to us. The philosophical move towards the definition of the concept of (natural) number in FA starts at the crucial, and extremely condensed first passage of $\S 62$, which opens by asking: "How, then, are numbers to be given to us?" And Frege ends BL (Appendix II) by stating: "The prime problem of arithmetic is the question, In what way are we to conceive logical objects, in particular numbers?" (143; "Way of conceiving" is one of the expressions Frege uses for his notion of sense, and it is virtually synonymous here with "way of being given".) This was not just a sort of a Socratic wondering about essences; it was rather a requirement implied by the conception of objectivity under discussion, and by the task of establishing the objectivity of arithmetic-the ways its basic truths are justifiable. Frege's logicism is, from this point of view, not only a reductivist program and a technical achievement, but also a philosophical discovery: it is the discovery that one can present the basic truths of arithmetic as being about objects, whose modes of presentation and the ways they are given to us as logical objects justify these truths.

This is true of logic as well. The basic truths of logic (e.g. of BL) are not provable, and yet claiming them to be analytic means that they are justifiable. This was established in previous sections. What I have proposed in the present one is that they are justifiable by explicating the modes of presentation of "their objects" - the things they are about. This, I have suggested elsewhere, ${ }^{24}$ was Frege's main reason for recognizing "logical objects", like extensions of concepts and truth-values, and for incorporating Sinne-modes of presentation-into logic, conceived in the wide sense as the theory of justification. Truth-values are given to us, Frege thought, in ways that are (partially) expressed by the basic truths of propositional logic; and extensions - by those of predicate logic (including axiom V of BL). The idea is that the basic truths of logic and arithmetic are secured their objectivity (and their being analytic) by being justifiable—not by proving them (which is impossible), but by

\footnotetext{
24 Bar-Elli (2001).
} 
presenting them as expressing features of the Sinne-the ways their objects are given to us. This is also why Frege was so troubled by the inconsistency pertaining to his axiom V of BL: It was not just a logician's worry about inconsistency; it presented also a deep philosophical concern. For, without this axiom, he saw no way in which classes-extensions of concepts and functions - are given to us, and no way in which numbers are given to us; and without this-no justification for the axioms governing them, and no basis for the objectivity of arithmetic.

\section{Analytic in the Narrow Sense and Analytic in the Wide Sense}

In the narrow sense, justification in mathematics and logic is basically a proof: a truth, accordingly, is analytic in the narrow sense, if it has a proof, which relies only on general logical laws and definitions. It is a priori, in the narrow sense, if it has a proof, which relies only on general laws (not necessarily logical). The wider sense of justification we have alluded to suggests a wider sense of analytic and a priori in which we can say of the axioms of logic that they are analytic, and of the axioms of geometry that they are (synthetic) a priori, in agreement with Principle J. We could then introduce these wider notions of analytic and a priori thus: A truth is analytic if (a) it is provable from general logical laws and definitions, or (b) it is a logical law, which is not in need of such a proof, because it is justified by dint of being self evident in expressing features of the modes in which the things it is about are given to us. The definitions concerned in (a) raise grave difficulties. They are usually not just unconstrained stipulative definitions (in which case any consistent first order theory would become analytic), but are what Frege calls "analytical definitions", which must satisfy severe philosophical constraints. I cannot expand on this here (see notes 27 and 30). Analogously (without the restriction to logical laws), a truth is a priori (in the wide sense) if (a) it is provable from general laws, or (b) it is a general law, which is justified in being self evident by expressing features of the modes in which things it is about are given us.

In thus speaking of the things a truth is about, the "things" concerned may be either objects (including extensions or classes) or functions (including concepts). It must also be remembered that Frege held a quite special view about what general truths are about-namely, that they are about functions (concepts). The universality of logic, for Frege, does not consist, as some people think, in its being about "everything" - truth-values, concepts, extensions, chairs, flowers and whales. No. A logical law is not about any chair, or any flower or any whale. This is clear concerning the laws of propositional logic, which, in the mature Frege, are about truth-values. But it is also true about those of predicate logic. Unlike many postTarskian views, a (universally) quantified law is, for Frege, not about the values of its bound variables, but about concepts, or, after introducing axiom $\mathrm{V}$ of BL, about extensions of concepts. ${ }^{25}$

I have also spoken about axioms as expressing "features" of the ways the things they are about are given to us. There is a hierarchy here. Speaking of concepts,

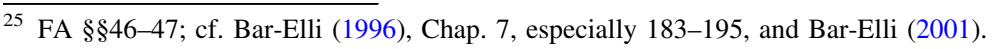


logical axioms express the most general and abstract features of the ways any concept is given to us - the concepts of a straight line, flower and whale included. Each of these, however, has special other features of ways it is being given, which are the business of other branches of knowledge to express. And where the branch is axiomatic, like Euclidean geometry, they may be expressed by its axioms. The special status of logic in this hierarchy is the root of the distinction between analytic and other a priori truths.

At the beginning we have remarked that in light of principle $\mathrm{J}$, it might also seem that there are singular factual truths, which, unless we appeal to non-deductive ways of justification, would be neither synthetic nor a posteriori. This is also hard to accept, and is definitely not Frege's position. The wider notion of justification we have tried to explain can open a way of accounting for this as well. For, it seems that some factual (e.g. perceptual) truths can also be justified by expressing aspects of the modes in which their objects are given to us. "This tree is green" can be justified, in appropriate conditions, by looking at the tree. And this may be regarded as justification because of the ways in which colors (and trees) are perceptually given to us. ${ }^{26}$ Again, discussing this in detail, however, would take us too far from the ostensive topic of this paper.

\section{Analyticity: The Kantian Heritage, Frege and Carnap}

The notion of analytic has a long history into which we shall not plunge here. But in order to clarify my point about Frege's notion of analytic and the special form of justification the analyticity of axioms evoke, it would be profitable to briefly survey two other landmarks in its history-Kant, on the one hand, and Carnap on the other. For Kant, a judgment is analytic when the concept of its subject includes the concept of its predicate. Kant connects this, in a way which is not entirely clear, with the "law of contradiction". In a famous passage of his Critique of Pure Reason (Kant 1933) he writes:

In all judgments in which the relation of a subject to the predicate is thought [...] Either the predicate B belongs to the subject A, as something which is (covertly) contained in this concept A; or B lies outside the concept A, although it does indeed stand in connection with it. In the one case I entitle the judgment analytic, in the other synthetic. Analytic judgments (affirmative) are therefore those in which the connection of the predicate with the subject is thought through identity (B10, p. 48).

Kant then speaks of synthetic judgments as "expanding" our knowledge, while analytic ones are merely explicative, analyzing the subject-concept into what is already thought in it. A judgment is a priori, for Kant, if its knowledge is independent of experience (ibid. B2-3). To many, Kant's formulation intermingles, quite confusingly, logical, epistemological and even psychological terms. But it

\footnotetext{
${ }^{26}$ Cf. Frege's discussion of "snow is white" in FA, §26. For an elaborated discussion, cf. Bar-Elli (1996), 35-43.
} 
suggests, as generally conceded, that the analyticity of a judgment concerns its content: the inclusion of one concept in another; its apriority-the way its truth can be known.

Frege probably thought otherwise. In $\S 3$ of FA he emphasizes that according to him the distinction between the analytic and the synthetic, like the one between a priori and a posteriori, concerns not the content of a judgment but its possible justification. To this he attaches a note saying that by this he means to state clearly what other writers, notably Kant, have meant. Whether Frege was right about Kant or not, it is clear that on his own view the notion of analytic pertains to the justification, not the content, of a judgment. It is worth mentioning here that Frege's footnote does not concern his "definitions" of analytic etc. as many have thought (cf. Dummett FPM 1991, Chap. 3), but only his saying that they pertain to the justification of a judgment. Hence, this note is no basis for thinking that Frege underrated or was not fully aware of the novelty of other respects of his notions of analytic, etc. and of the differences between them and those of Kant.

As many have observed Kant's notions, in being restricted to subject-predicate judgments, are of a rather limited applicability. His notion of concept and the meaning of "containing" in his formulation are not clear. Evidently, Frege could not be satisfied with these formulations. In any case, it was important for Frege to emphasize that his notions concern the possible justification of a judgment, and it is in this connection that he formulates principle $\mathrm{J}$.

Moreover, in the conclusion to FA Frege clearly states that given Kant's notions of analytic and synthetic, the conclusions he [Frege] draws from his definitions ought to be regarded as synthetic! (FA 101). This statement, so often ignored in the literature, clearly suggests that he was not only sharply aware of the novelty of his notion of analyticity and of his re-construing the analytic synthetic distinction, but that he saw it as crucial for appreciating the difference between his position and Kant's on arithmetic.

Carnap, on the other hand, introduced a notion of analyticity, which is clearly concerned with propositions (not judgments) and meaning relations between the words comprising them. Hence, this notion pertains to the contents of propositions, not to ways of their justification. Following him this has become the prevalent notion of analyticity, both by adherents and opponents. A proposition is analytic, on this conception, if it is true in virtue of the meanings of its component words. By "meaning" here is meant conventional meaning of a word in a language. Within his formal semantic systems Carnap explicated this notion in terms of his distinction between the extension and the intension of a term: Analyticity and the meaning relations constituting it are a matter of intensions. While truth (or falsity) of a regular non-analytic proposition, like "Socrates is wise", is a matter of relations of the extensions of its terms, namely Socrates and the extension of "wise", the truth of an analytic one, like "A square is a rectangle" depends only on the intensions of these terms, which is a linguistic matter. In order to know its truth one needs not examine facts (extensions-relations) but simply understand the proposition-know the conventional meaning of "square" and "rectangle" (Carnap 1956).

Obviously, when the terms concerned are not defined by stipulation, but are meaningfully used, determining their intensions and the analyticity of propositions 
containing them, may require an analysis. But this, on Carnap's conception, is an analysis of linguistic meanings, not of matters of fact (except facts of linguistic usage). In a formal semantic system such an analysis can sometimes be expressed by a set of "meaning postulates", on the basis of which the analyticity of corresponding propositions may be proved. His position on this raised a vehement critique and opposition, notably by Quine, who maintained that this kind of distinguishing matters of facts and matters of linguistic meanings cannot be generally maintained.

I mention this quite well known story, not in order to enter a discussion of it, but merely as a background for a sharper appreciation of Frege's notion of analytic and the point I have made concerning it. Besides their differing about whether analyticity concerns content or justification, there is also an important difference between Frege's sense (Sinn) and Carnap's meaning (intension). For Frege, the truth of axioms, and their being self-evident are rooted, I have proposed, in the senses (Sinne) of their components, i.e. in the ways their references, the things the axioms are about, are given to us. This could lead us to think that his position is quite close to that of Carnap (as Carnap himself, who studied with Frege, thought). But I think that this is a mistake: Meaning relations, for Carnap, are between the conventional meanings of words; they are entirely linguistic. Things in the world and ways they are given to us are not in the game. Fregean senses, on the other hand, consist of our cognitive relations to things in the world; they are ways in which things in the world are conceived by us. If we imagine language and the world as two planes in space, we could say metaphorically, that Carnapean meaning relations are confined to one plane-the linguistic. Fregean sense, in contrast, relate both planes with one another. They are modes in which things in the one are conceived and expressed in the other. This is the deep reason why it was so important for Frege to emphasize that his notion of analytic is concerned with epistemic justification-the ultimate grounds of truths and of justifying claims to knowing them. ${ }^{27}$

\section{The Significance of Frege's Notion of Analyticity: Truth}

I have been arguing that in contrast to the standard interpretation, Frege's notion of analyticity is based on justification, and that justification is not solely deductive or inferential: there also is a sort of "epistemic" justification, in which a statement is justified by dint of the senses (Sinne) — modes of being given-of the things it is about. In this way one can understand the analyticity of the axioms of logic, the apriority of the axioms of geometry, and the aposteriority of singular factual

\footnotetext{
27 This may have escaped Boghossian. He distinguishes an epistemic notion of analyticity from a metaphysical one, and says of the former: "According to Frege, a statement's analyticity (in my epistemological sense) is to be explained by the fact that it is transformable into a logical truth by the substitution of synonyms for synonyms." He talks of this as a "semantical condition". However, the relevant kind of definitions (what Frege calls "analytical definitions") are not statements of synonymy or sameness of conventional meaning, but explications of modes of being given. Therefore, "semantical" in Boghossian's formulation also seems inappropriate. I elaborate on it in my (2009), Chap. 7. See also n. 30.
} 
statements, all of which are unintelligible, if the only form of justification is deductive inference.

Getting clear about Frege's exact view is important enough. But one could still wonder what philosophical importance this may have beyond the details of Frege's exegesis. Suppose I am right about Frege's position; is there, beyond exegetical meticulousness about his position, a special significance or advantage to his position over the standard one? I believe the answer is positive and shall try to explain some additional aspects of its significance.

A general background question here pertains to the significance of the notion of analyticity in general-not particularly that of Frege's. Analyticity has been regarded a major philosophical topic (even if not under this name) at least since Leibniz and Hume. It was regarded by Quine as one of the two important "dogmas of empiricism", and many regard it as at the centre of the main business of philosophy-conceptual analysis. It may still not be clear why it was regarded to be of such a philosophical significance, and in what the significance of the general problem of analyticity consists. With regard to this very general question I shall generally say that the significance of the notion of analyticity lies in the challenge it poses to our conception of truth and the relationship between truth and meaning. For many realists (and empiricists) truth consists in some "correspondence" with the world. For many idealists (and rationalists) it consists in an inner notion of coherence within our thoughts, ideas and beliefs. This is a large and metaphysically loaded cleavage. However, either school (or best proponents of it) seems to subscribe by a principle we may call the "homogeneity of truth": Whatever your metaphysical view of truth is, it should not recognize radically different kinds or notions of truth but should be homogenous across the board (of propositions or thoughts).

Now, for idealists and rationalists the significance of analyticity is obvious: it can be, and often has been, regarded as the paradigmatic case of truth in general. Leibniz, for instance, thought that any truth is basically analytic-of the form (he called identity) $\mathrm{AB}=\mathrm{A}$ (what is $\mathrm{A}$ and $\mathrm{B}$ is $\mathrm{A}$ ). Truth, essentially, is the inclusion of the predicate concept in the subject concept. Contingent and singular truths seem in this respect problematic, and Leibniz devoted much effort to explain their conformity to his general conception of truth, in terms of the distinction between finite and infinite analysis of concepts, and the claim that their "analytic" character is revealed only by infinite analysis, which is unavailable to us, and which only God can see.

The important point for our concerns is not only the centrality of analyticity in Leibniz's conception of truth, but also that Leibniz's theory seems to be motivated by an insistence on a homogenous notion of truth-at bottom we have one homogenous notion of truth-the inclusion of the predicate-concept in the subjectconcept - which is in principle analytic. His metaphysical effort was to explain, on this basis, two things: contingency (or what appears to be contingent), and the realistic character of his analytic notion of truth. ${ }^{28}$

\footnotetext{
$\overline{28}$ This has been argued in detail in Bar-Elli (1985).
} 
There are many variants and characterizations of the realistic position (Aristotle's, Frege's, Wittgenstein's Tractatus and Dummett's are notable examples). But it seems that on all variants the gist of a realistic position is that the world and things in it are the essential and decisive factors in determining the truth or falsity of our sentences and thoughts: "In order to tell whether a picture [proposition, thought] is true or false we must compare it with reality" (Wittgenstein (1961): Tractatus, 2.223). ${ }^{29}$ "It is impossible to tell from the picture alone whether it is true or false" (2.224). And the world, in this determination, is "autonomous", and is not subject to or constrained by anything. This basic idea is crucial for a realistic conception of truth. I shall call this in short "the autonomy of the world".

Now, analyticity poses a problem for this conception of truth, for it seems that in the case of analytic propositions the world is not playing any role at all-these propositions are true, according to the standard conception of analyticity, by dint of the meanings of their terms alone, or in Quine's phrase-an analytic truth is "grounded in meanings independently of matters of fact" (TD). Quine had here mainly Carnap in mind, but he almost repeats this formulation when summarizing even Kant's view: "Kant intent can be restated thus: a statement is analytic when it is true by virtue of meanings and independently of facts" (ibid).

But what then is the meaning of "true" here? And what is the connection between such truths and the regular realistic conception of truth as described above? The notions of meaning and of relations between meanings are problematic and have been attacked by many philosophers. But even disregarding this, and supposing that we have some satisfactory notion of meaning and of meaningrelations, what then do such meaning relations have to do with the autonomy of the world in determining the truth of propositions, as stated above?

This then is the challenge analyticity poses to our conception of truth. "Challenge to our conception of truth" should be underscored. Quine, as is well known, opposed the very intelligibility of the standard notion of analyticity. The gist of his opposition was based on his doubts concerning the intelligibility of the notions of meaning and necessity, on which this conception allegedly relies (e.g. in Carnap). He devotes much space to showing that one cannot define analyticity in terms of these notions in a non-circular way. This opened a live and wide discussion of these matters for at least a generation. Our questions here, let us emphasize, are different. Suppose there is a satisfactory retort to Quine's strictures, and we have an intelligible notion of meaning, on the basis of which we can speak of meaningrelations, and can talk of a certain property of propositions-analyticity. Why should we think that this property is related to truth? Why should we think that propositions having it should be true? And if for some reason we insist on talking this way, in what sense are they true, and what would be the connection between this "analytic truth" and the realistic notion of truth we were talking about before? For it seems that the role of the world, its objective autonomy, which was the core of the notion of truth, fades out and disappear here. The world and its various situations

\footnotetext{
${ }^{29}$ Reality, in the Tractatus is the totality of facts, or facts in logical space, and facts are "existing states of affairs". All these raise notorious questions we shall not deal with.
} 
do not play here a role any longer, and suddenly, in their stead, we have conventional meanings and truth by virtue of meanings.

On this general background we can better understand, I believe, a main significance of Frege's notion of analyticity. In contrast to the sort of duality in the conception of truth implied by the standard conception of analyticity, the Fregean conception succeeds in maintaining the homogeneity of the concept of truth. There are no different kinds of truth—one "by virtue of facts" in the world and one "by virtue of meaning" and meaning-relations. There is rather one notion of truth, and the distinction between the analytic, synthetic, a-priori and a posteriori concern kinds of justification and bases of knowing these truths. There is no appeal in this explanation to a notion of "truth by virtue of meaning", but only to various justification-procedures, which we need recognize in any case.

One could object here that "by virtue of meaning", in the standard conception, is also a procedure of justification, and that therefore the difference between the standard conception and the Fregean one is not as substantial as I represent it. But this, I believe would be wrong, and the difference in question remain valid: In the standard conception the world gets out of the game (of justification) and does not function at all in determining the truth or falsehood of analytic propositions. Not so in the Fregean conception. A truth, on this conception, is analytic if it has a justification relying only on logic and definitions. Both logic and definitions (in the relevant sense) concern, on Frege's conception, the world: Logic, for Frege, consists of truths; it is a universally true theory (of the world); and the definitions concerned in such a justification are not stipulative, or conventional determinations of meaning, but rather explications of the ways in which the defined (or what is denoted by it) is given to us. ${ }^{30}$ These ways of being given (Sinne) are rooted in the things in the world and their properties, and therefore the notion of truth that is founded on them leans, just like in regular truths according to the realistic conceptions, on the world, and things in it. Hence, the notion of truth involved in analyticity, on Frege's conception, is not, in principle, different from the "regular" notion, which respects the autonomy of the world, and according to which things in the world determine what is true.

The above point can be summed up as follows: The significance of the notion of analyticity lies in the kind of answer it suggests for the problem of apriority-how there can be truths whose knowledge does not depend on experience. The problem of apriority may be roughly stated thus:

\footnotetext{
30 This has been argued in detail in Bar-Elli (2009), Chap. 7 ("Definition and Analysis in Frege"), where it is shown that the course of argument of Frege's FA expounds a sophisticated view of the nature of philosophical analysis, in which analytical definitions (to be distinguished from "constructive" definitions) are part of a philosophical explication of ways in which the things concerned are given to us. This explication respects three fundamental principles:

1. The principle of about-propositions are about things referred to by their terms.

2. The context principle-one of whose implications is that securing a sense for a proposition guarantees meaning for its terms.

3. The principle of the explanatory value of sense-Explicating the sense of a term is explicating a way its reference is presented, which explains and justifies propositions about it.
} 
1. Truth consists in correspondence to facts (the realistic assumption).

2. Facts are known only by experience (the empiristic assumption).

These two seem to exclude what was taken to be an obvious truth:

3. There are many a priori truths - truths known independently of experience.

These formulations are very rough, and they are unfaithful to many of the philosophers concerned (including Frege). They are intended here just for a general picture I wish to draw, and can be adjusted in each case more carefully. In these rough terms, Carnap and the classical tradition answered the problem by denying (1): there are also truths "by virtue of meanings" (analytic truths). Their being true consists in meaning relations; not in correspondence to facts. Frege rejects this, and answers the problem by denying (2): There are objective facts, which are not necessarily known by experience, but by logic and reason alone. In this, Frege partly followed Kant who also denied (2) by proclaiming intuition (Anschauung) in addition to sensual experience as a source of knowledge. Frege had reasons against applying this to arithmetic and logic. I shall not go into them.

It is worth noticing, in this connection, that there is from this perspective an important difference between analyticity, in the standard conception, and necessity. In the standard conception of analyticity the world and its possibilities don't countthey are not in the game. In a necessary proposition, the world and its possibilities do count, though in a "degenerate" way-the proposition is true in all possible worlds. This is an edge point or a degenerate case of the classical realistic conception. The world does function here and determines the truth of the necessary proposition; the determination is degenerate though, in the sense that it is like a constant function-it is the same in all situations. In this sense, necessary propositions do not threaten the homogeneity of truth - the world, is a factor in determining the truth of a necessary proposition, and the latter is a function of the world, though a constant one.

Analytic truth, in the standard conception, is an altogether different story. The world and its possibilities do not function here at all-not that it is found out, at the end, to have a constant result. Therefore, "truth in virtue of meaning" is an altogether different game from "truth in every possible world", even though they may have extensionally the same results. Whereas in the case of necessity the proposition is true in all possible worlds - that is in $\alpha 1, \alpha 2, \alpha 3, \ldots$, the case of analytic truth is entirely different: there is no "true in $\alpha$ " there at all, and the different situations $\alpha$ are not in the game here from the very beginning. This is part of the reason why seeing a necessity often requires proof, and sometimes a very hard and complicated one. It is not so with analyticity in the standard conception (unless one stipulates necessary truths to be analytic). ${ }^{31}$

Frege's notion of analyticity, unlike the standard one, and like the above account of necessity, is couched in full harmony with the principle of the homogeneity of the notion of truth, and does not require or suggest the split between "truth by facts"

\footnotetext{
31 The point may be implied by (or at least connected to) Kripke's insistence to use "analytic" as narrower than "necessary". An analytic truth, he insists, is not only necessary, i.e. true in all possible worlds, but is so by virtue of its meaning (see Kripke 1972, p. 39 and note 63 on p. 122). "True by virtue of meaning" remain operative (and unclear).
} 
and "truth by meaning", characteristic of the standard conception. In this, Frege and Quine are proceeding with Leibniz in keeping up the homogeneity principle; the standard conception, Carnap and the notion of analyticity Quine attacks—are not.

Acknowledgments I have been benefited, in this research, from a grant of The Israel Academy of Science.

\section{References}

\section{G. Frege}

Begriffsschrift (Halle, 1879). Translated in From Frege to Goedel (J. van Heijenoort, ed.) 1967. Cambridge: Harvard University Press (Bs).

Die Grundlagen der Arithmetik (Breslau, 1884). The foundations of arithmetic (J. Austin, Trans.). Oxford: Basil Blackwell, 1954 (FA).

Die Grundgesetze der Arithmetik (Jena, 1893). The basic laws of arithmetic (M. Furth, part of volume I, Trans.). Berkley: California University Press, 1964 (BL).

Posthumous Writings. Oxford: Basil Blackwell, (1979) (PW).

\section{Other Writers}

Aristotle. (1941). Posterior analytics; metaphysics. In R. McKeon (Ed.), Basic works of Aristotle. New York: Random House.

Bar-Elli, G. (1985). Leibniz's conception of truth (in Hebrew). Iyyun, 34, 185-200.

Bar-Elli, G. (1996). The sense of reference. Berlin and New York: W. De Gruyter.

Bar-Elli, G. (2001). Sense and objectivity in Frege's logic. In A. Newen, et al. (Eds.), Building on Frege (pp. 91-111). Stanford: CSLI.

Bar-Elli, G. (2006). Identity in Frege's Begriffsschrift. The Canadian Journal of Philosophy, 36/3, $355-370$.

Bar-Elli, G. (2009). The fathers of analytic philosophy: Frege, Russell, Wittgenstein, Vol. 1: Frege: Logic, meaning, intentionality (in Hebrew).

Boghossian, P. A. (1996). Analyticity reconsidered. Nous.

Burge, T. (1998). Frege on knowing the foundations. Mind, 107, 305-347.

Burge, T. (2001). Frege on apriority. In A. Newen, et al. (Eds.), Building on Frege (pp. 53-87). Stanford: CSLI.

Burge, T. (2005). Truth, thought, reason. Oxford: Clarendon Press.

Carnap, R. (1956). Meaning and necessity. Chicago: Chicago University Press.

Dummett, M. (1981). The interpretation of Frege's philosophy. Duckworth.

Dummett, M. (1991). Frege philosophy of mathematics. Duckworth.

Kant, E. (1933). Critique of pure reason (N. Kemp Smith, Trans.). Macmillan.

Kripke, S. (1972). Naming and necessity. Cambridge: Harvard University Press.

Quine, W. V. O. (1953). Two dogmas of empiricism, reprinted in his From a logical point of view (2nd ed.). Harvard University Press, 1961 (TD).

Wittgenstein, L. (1961). Tractatus Logico-Philosophicus (Pears \& McGuinness, Trans.). Routledge and Kegan Paul. 